\section{A study measuring the effectiveness of outreach work, as a means of increasing public library use and social inclusion in order to meet Public Service Agreement targets.}

\author{
Wendy Molyneux
}

\begin{abstract}
Author
Wendy Molyneux is the Service Development Officer for Warrington Library, Museum and Archives Service. E-mail:wmolyneux@warrington.gov.uk
\end{abstract}

\begin{abstract}
In April 2002, Warrington Borough Council entered into a three year Local Public Service Agreement aimed at improving public services throughout the Borough. Warrington Library, Museum and Archives' involvement was to increase the number of issues, visitors and newly registered members to libraries in six socially deprived wards - creating the outreach post of Service Development Officer to carry forward strategic plans. At the end of the agreement, an evaluative case study was undertaken to measure the effectiveness of outreach work as a means of increasing public library use and social inclusion by using methodological triangulation. The findings confirmed the success of meeting the targets and support for the Service Development Officer post which has been permanently mainstreamed by Warrington Library, Museum and Archives Service and contributed to the development of a model to measure future projects.
\end{abstract}

\section{Acknowledgements}

The author is grateful to Martin Gaw, Head of Warrington Library, Museum and Archives Service for his continual support. Thanks also to Peter Lea at Manchester Metropolitan University for his help and advice and to Warrington Borough Council's Policy and Research Department.

\section{Introduction}

Central Government's vision is rooted in the principles of social inclusion - creating initiatives, forming partnerships and setting national standards throughout all sectors reaffirming their commitment to improving people's quality of life.

The Local Public Service Agreements (PSAs) are a new way for local authorities and Central Government to work together - by cutting across the traditional boundaries of policy and organisation and challenging the way services are delivered.

Set across a three year time span, the agreed targets reflecting a mix of (usually twelve) local and national priorities, are intended to 'stretch' the authority's performance with financial support from Central Government including a pump-priming grant at the outset and a performance reward grant for successful achievement.

Warrington became a unitary authority in 1998 and with a population in the region of 191,000 was recognised as a fast-growing and thriving town. However, wide contrasts of social and economic positions revealed -

- Home ownership was above the national/regional average, although $36 \%$ of the population lived in areas that scored as being deprived.

- Although with a global business identity in service and technology industries and unemployment levels below the national/regional average, it was estimated 30,000 people were dependent on Income Support.

- Overall crime levels were generally below the national/regional average with pockets of higher crime rates within the more densely populated areas.

- Attendances for Warrington Libraries were below the $25^{\text {th }}$ percentile for performance for BVPI 117. (Warrington Borough Council, 2002) 
Against this backdrop, targets were set within the Council's Best Value and improvement plans framework aimed at improving services and tackling social exclusion. The purpose of PSA Target 12 (Warrington Borough Council, 2002) was to enhance and develop lifelong learning by addressing poor library usage and membership in the six major deprived wards of the Borough - in effect, involving three static libraries Warrington Central, Orford, Padgate and some of the areas covered by the mobile routes.

Warrington Library, Museum and Archives Service employed an outreach worker to support attainment of the PSA by raising awareness of the service, making contact in non-library venues, organising events, contributing to ward newsletters and overall pro-active service development.

It is felt that the findings from this study and the subsequent development of a model are beneficial not only to Warrington Library, Museum and Archives Service but to the wider public library profession.

\section{Literature review}

A comprehensive review of literature surrounding outreach work, public libraries and social exclusion, in the UK, helped explain social disadvantage and investigated ways public libraries can increase inclusion. This helped to identify significant issues and focus on the objectives of the research.

Although there was a range of descriptive narrative regarding specific projects and good practice from library authorities to be found, there appeared to be little that was thoroughly assessed and documented which, it was felt, makes this a timely study.

One major facet that was confirmed by investigating relevant literature is that whilst public libraries contribute to key strategic Inclusion, Learning and Regeneration initiatives, historically, they have always found difficulty in attracting users from the very lowest social groups. (Black, 2000) This suggests the need for them to adopt a proactive role by finding new and different ways of working - combining national policy and local action leading to fundamental changes in the manner in which they interact with the communities they are meant to serve. An argument brought to the fore was that the most successful ways to achieve this is to work inside and outside of library premises, building partnerships and redirecting resources to tackle, specific, targeted social exclusion issues.

Recognising the benefits of this, by employing an outreach worker it was felt there would be an opportunity to go beyond passive consultation with existing users and actively engage with the targeted excluded communities.

\section{Rationale of targets and action plan}

PSAs allow authorities to have the freedom to utilise the pump-priming in the way they feel it would be most useful providing targets reflecting specific and measurable improvements in outcomes compared with performance that could have been expected without a PSA.

The three static libraries in the deprived wards had been showing an average falling trend in visits of $24.35 \%$ as shown in table 1 . 


\begin{tabular}{|c|c|c|c|c|c|}
\hline & $\begin{array}{c}\text { actual } \\
\text { visits } \\
1999 / 2000\end{array}$ & $\begin{array}{c}\text { actual visits } \\
2000 / 2001\end{array}$ & $\begin{array}{c}\text { actual } \\
\text { visits } \\
2001 / 2002\end{array}$ & $\begin{array}{c}\text { \% decline on } \\
\text { 1999/2000 } \\
\text { figures }\end{array}$ & $\begin{array}{c}\text { LPSA } \\
\text { target } \\
\mathbf{2 0 0 4 / 2 0 0 5}\end{array}$ \\
\hline Orford & 45,448 & $\begin{array}{l}39,000 \\
(-15 \%)\end{array}$ & $\begin{array}{c}38,948 \\
(-0.14 \%)\end{array}$ & $14 \%$ & 42,842 \\
\hline Padgate & 110,656 & $\begin{array}{l}72,644 \\
(-35 \%)\end{array}$ & $\begin{array}{l}52,884 \\
(-28 \%)\end{array}$ & $52 \%$ & 58,172 \\
\hline Warrington & 278,876 & $\begin{array}{c}231,868 \\
(-17 \%)\end{array}$ & $\begin{array}{c}237,224 \\
(+2 \%)\end{array}$ & $15 \%$ & 260,946 \\
\hline Totals & & $\begin{array}{c}343,512 \\
(-21.03 \%)\end{array}$ & $\begin{array}{c}329,056 \\
(-4.25 \%)\end{array}$ & & 361,961 \\
\hline
\end{tabular}

It was anticipated without the PSA, visits to libraries would continue to decline. The object of the PSA was to increase the number of visits by $10 \%$ over the three year period thus seeing an upturn in the decline to $16.78 \%$.
There had been an average falling trend in issues at the static libraries of $19.16 \%$ since $1997 / 8$.

Table 2

Actual issues figures for 1997-2001/estimated figures for 2001/2002

\begin{tabular}{|c|c|c|c|c|c|}
\hline $\begin{array}{c}\text { actual } \\
\text { issues } \\
1997 / 1998\end{array}$ & $\begin{array}{c}\text { actual } \\
\text { issues } \\
1998 / 1999\end{array}$ & $\begin{array}{c}\text { actual } \\
\text { issues } \\
1999 / 2000\end{array}$ & $\begin{array}{c}\text { actual } \\
\text { issues } \\
2000 / 2001\end{array}$ & $\begin{array}{c}\text { estimated } \\
\text { issues } \\
2001 / 2002\end{array}$ & $\begin{array}{c}\text { LPSA } \\
\text { target } \\
2004 / 2005\end{array}$ \\
\hline 596,224 & 548,171 & 481,346 & 481,958 & 450,539 & 482,077 \\
\hline
\end{tabular}

The proposal was to reverse this by an increase of $7 \%$ on figures estimated for 2001/2002.

At the time the PSA was agreed, the population of Warrington was 190,830; the average library membership throughout the Borough (including the deprived wards) was $35.3 \%$. The average percentage of residents in the non-deprived wards who were library members was $39.65 \%$. However as this was considerably lower in the six most deprived wards, it was proposed to increase the number of registered library members in these areas by $13 \%$.

A Pump Priming Grant of $£ 93,500$ was allocated to Warrington Library, Museum and Archives Service with the aim that the funding would not only halt the decline in these three areas but turn it round and start bringing performance back to previous levels. (Warrington Borough Council, 2002)

\section{Purpose of the study}

In order to determine choice of strategy, it was necessary to clarify the overarching purpose of the study. The SDO's role was to promote learning, encourage reading and literacy, help build community identity and add to the cultural life of the Borough. This was achieved by arranging events and activities both inside and outside of library buildings, making contact with the community in non-library venues, eg. attending residents' meetings and community fun days, planning new mobile routes and contributing to community and Borough 
newsletters. It was also necessary to build and develop partnerships with other organisations. The aim was "concerned not only with assessing worth or value but also with seeking to assist in the improvement" (Robson, 2002, p.205) of public library outreach work ultimately developing a model for future use. Consequently, the main purpose was that of an evaluation.

However, this is not to suggest the intention was simply a matter of conducting a summative evaluation to determine how far the objectives of the study were met but systematically collecting information .... "for use by specific people .... to reduce uncertainties, improve effectiveness and make decisions"; (Patton, 1982)thus combining formative evaluation to help in the development of future programmes.

\section{Data collection and analysis}

It can be argued that traditional performance indicators, which rely on statistical evidence, cannot solely be used to measure the success of outreach projects. Therefore, methodological triangulation combining quantitative and qualitative approaches was adopted.

Documentary sources, including local and national plans and reports, provided the necessary information to establish the background, overall rationale and agreed targets for the PSA.

Quantitative data, determining issues and newly registered members target achievement, was obtained by analysing statistical evidence generated by the library management system, Dynix whilst visitor statistics were collected by means of electronic eyes. Numeric data was accumulated over the three year target period, collated onto Excel spreadsheets and analysed allowing comparison of target and actual figures to be obtained.

Qualitative data was obtained by collecting opinions from a study population including staff from thirteen static libraries, the mobile library and a range of community workers. To determine the effectiveness of the outreach worker post, face-face interviews were conducted. The major advantage of this method is in its adaptability which, in one form or another, is important in case study research.

To determine key people to consult and obtain guidance on questions to ask it was necessary to develop a 'consultative' relationship with others in a privileged position by conducting an elite interview. (Gilham, 2000) Primary accountability was to that of the Head of Warrington Library, Museum and Archives Service who held a different perspective and was able to direct the research. However, as he joined the Service after the PSA had been agreed, fuller breadth and depth of background information was obtained by interviewing the Principal Libraries Manager.

Whilst structured interviews ask standardised questions with fixed wording in a pre-set order, the intention was to explore in-depth what respondents felt about the outreach worker post. Suggestion therefore was that conducting unstructured interviews would be a suitable method to use. However, heeding warning that this is "a skilled task .... not to be undertaken by untrained researchers" (Moore, 2000), it was decided to combine elements of both and conduct face-to-face, semi-structured interviews.

A framework of predetermined, mainly openended questions with the flexibility to modify them necessary by using non-directive probes (thus allowing additional information to be gained) was used. Reflective listening, by repeating back what had been stated by the interviewee, addressed any ambiguities.

The interview schedule was trailled by discussing key questions with Warrington Borough Council's Research Officer to ensure they were productive, clear and concise - each distinctly dealing with a separate facet of the study and piloted prior to purposively sampling a range of stakeholders.

To address the potential threat of bias which may occur when using a non-random method, a stratified sampling frame was used which 
included the Head of Service, the Principal Libraries Manager, eight professional staff (including three who were part of an original steering committee for the PSA, two stock specialists and two librarians in charge of the PSA libraries), eight non-professional library staff involved in the PSA and three library staff from other satellite libraries.

It was recognised that outreach work should be conducted through partnership and collaboration between libraries and other organisations Reliability of findings was ensured by interviewing representatives from community groups. To this end a member from Surestart was able to voice opinion on behalf of families with young children; and a member of Positive Futures (with the remit of working with young disadvantaged people between the ages of twelve and sixteen) and a Community Development Officer (CDO) working across the board although primarily with adults were both interviewed.

All considerations were addressed before undertaking the research and interview sessions to justify the proposal and obtain respondents' consent (confirming the voluntary basis of their participation and guaranteeing confidentiality) thus ensuring the study was undertaken within an ethical framework. The interviews were audio taped, subsequently transcribed and entered onto a conceptual matrix for analysis. It was felt, although face-to-face interviewing proved to be extremely time-consuming, this was outweighed by the opportunity to clarify issues and reveal findings which may have remain hidden if a large scale survey had been conducted.

\section{Quantitative findings}

At the end of the PSA period, Warrington Library, Museum and Archives Service was pleased to report that statistical evidence confirmed all targets had not only been met but exceeded.

It was recognised that the People's Network contributed to an increase in visits, especially at Warrington Central Library and although registration is not required to use the computers, members of the public are encouraged to join on request to use the IT facilities. However, allowing library premises to be used out-ofhours by youth and community groups, organising events inside libraries, seeking ways to work cross-domain with the Museum and building up contacts with schools encouraging class visits and taking part in school events also had significant impact on the overall total.

The delivery of a new, large mobile van at the beginning of 2004 saw it being widely used to promote the service at community events and in the town centre. In addition, during this time, the provision of a fortnightly service to the borough of Halton ceased allowing more routes to be added to the existing itinerary, the majority of which were sited in the deprived wards.

The PSA funding afforded the opportunity for an innovative project, Books $4 U$. This pilot scheme of deposit book collections relocated to non-library venues was a major contributing factor in the upturn of issue figures.

Incentives allowing a free audio visual loan when registering and special offers throughout the year were also instrumental in the rise in numbers of issues along with a new policy allowing the return of items anywhere across the Borough.

\section{Qualitative findings}

Interview questions were designed to determine respondents' awareness of the PSA, their definition of social exclusion, ways they felt libraries could increase use by those who are socially excluded and their perceptions of the role of an outreach worker.

Staff were asked to explain the purpose of the PSA and identify the targets and libraries involved in the agreement.

Although $95 \%$ of respondents were able to identify the libraries involved in the PSA, only $32 \%$ were aware of all of the concepts involved. "It's three years since we started - I can't 
remember" poses the question as to whether staff were briefed thoroughly in the beginning or at regular intervals or if they lacked a feeling of participation in the project.

When asked - What is meant by social exclusion? and How do you feel libraries can increase use by those who are socially excluded? - it was widely acknowledged there are multi-dimensional causes and consequences of social exclusion which may prevent people from accessing services that others take for granted. Half of the respondents interviewed felt that social exclusion isn't about groups of people but about an individual's self perception.

This led to asking respondents to identify what is meant by outreach work and how they felt about the role of an outreach worker.

Comments such as ....

"we can do all the good things we want inside the library but unless you are going out and telling people they won't know what's on offer" and "it's a big institution so the more of a human face we can put on it makes people welcome" offered support for the role.

However, it was felt that the success of the post "depends of the quality of the worker".

It was also documented that work conducted outside of library premises by the outreach worker must be backed up by work in the library - "you need it inside as well as outside". This gives weight to the observation that getting the human resource foundations right are of utmost importance. This includes targeted staff training to meet the needs of those who may be marginalised and a positive attitude building on the fundamentals that "people need to feel welcome, important, comfortable and understood".

In addition, concern was raised by $26 \%$ of respondents who felt there is the danger other staff may perceive responsibility rests solely with one person so that, in effect, the role of an outreach worker should be that of a co-ordinator - seeking new audiences, building up connections and involving other staff to carry those contacts on.
When asked - Do you feel you were kept adequately informed of outreach approaches? $42 \%$ of respondents were unaware of any outreach work taking place until the latter half of the agreement. This may be due to an observation raised by $38 \%$ of professional staff who felt that "a lot of time was wasted at first trying out very small things rather than big and bold things". Although 58\% felt they had been informed as much as they needed to be, this is an ambiguous statement which could imply that staff felt outreach work was something that didn't involve them.

Finally, respondents were asked - What, if any, impact has outreach work had on achieving targets? It was recorded that measuring methods could have been used to precisely quantify the direct effects of outreach work by more initial strategic planning, eg. borrower codes could have been created to track usage by people who joined the Service at outreach events. However, the overwhelming feeling was "you don't have to have fantastic results on paper to justify the need .... it's about enriching people's lives".

\section{Outcome of the evaluation}

Taking into account the statistical evidence which relied on meeting very stringent targets coupled with positive support from other library staff not involved in the study through consultation and anecdotal feedback, it was decided to permanently mainstream the position of Service Development Officer as from April 2005.

\section{Limitations to the study}

By using triangulation, the researcher is satisfied the strategy and methods implemented produced reliable findings. Every attempt was made to avoid bias and eliminate error during data collection and by sampling varied stakeholders, it is felt, it would be fair to judge the reliability of results as being representative of the wider study population.

Semi-structured interviews were satisfactorily conducted. However, it is felt that data would have been more difficult to collect and analyse 
if the sample population had been greater. If this had been the case, the suggestion would have been to adopt a more structured interview schedule reducing the need to transcribe interviews which was extremely timeconsuming.

Although it has been argued that "case study results are specific to the particular context in which the study took place", (Lecompte, M.D. and Goetz, J.P., 1982) it is felt sufficient generalisability has resulted allowing for the development of the following generic model (figure 3) which can be used to ensure successful project achievement.

The commitment of senior management is the major priority to ensure adequate resources and budgets are allocated.

It is necessary to strategically plan and organise at the outset taking into account, as far as practicable, all possible eventualities. This should include a clear rationale, vision of the outcome, how the project will be delivered and the ways in which evidence will be collected. Although it is time-consuming, and there can be a strong temptation to forge ahead, initial planning is crucial for success and it is necessary to consider each of the stages carefully as without a clear vision of where we want to go - how will we know if we've arrived?

The flow arrows demonstrate the importance of how lines of communication should be used, i.e. at all levels, cross domain, with partners and communities, not only talking but actively listening to the opinions, concerns and needs of other stakeholders. This is vital throughout all stages of planning, implementing and the final crucial step. - evaluating; for it is monitoring and receiving feed-back that allows for reflection and subsequent improvements to be made.

\section{Conclusion}

Central Government have placed social exclusion issues high on their list of priorities. Local Public Service Agreements (PSA) have been developed to ensure that local and Central Government work together to deliver services which take into account measures to make improvements to peoples' quality of life based on, usually, twelve key outcomes.

Central Government provides initial Pump Priming funding with the possibility of receiving a Performance Reward Grant for achievement giving authorities focus and incentive to meet stringent targets centred around local and national priorities.

Warrington Borough Council entered into a three year PSA in April 2002 with targets aimed at making significant contributions to improve social inclusion in the deprived wards of the Borough.

Warrington Library, Museum and Archives Service's stake in the PSA was to increase the number of visits, issues and registered members in three static libraries, Warrington Central, Orford and Padgate, and some of the areas serviced by the mobile library; hence enhancing and developing lifelong learning.

An outreach worker post was created to implement the strategic objectives that had been set to challenge barriers to use and raise the profile of the service; thus the Service Development Officer acted as a link from the socially disadvantaged communities into the library providing the opportunity to challenge the way services were delivered - taking the experience of what libraries have to offer outside of the building by active involvement in community activities, forming partnerships and seeking ways to encourage library use.

This provided the opportunity to challenge the way services were delivered - taking the experience of what libraries have to offer outside of the building by active involvement in community activities, forming partnerships and seeking ways to encourage library use.

A review of literature highlighted the issue of social exclusion in contemporary Britain, particularly in relation to public libraries. 
The background and overall rationale for the study was provided by documentary analysis and consultation with the Head of Warrington Library, Museum and Archives Service and the Principal Libraries Manager. Documentary analysis also confirmed the targets figures which had been set for the library service.

Quantitative data generated by the Library Management System, Dynix, and supplied by the Systems Administrator confirmed

- a marked improvement in the number of visits to the static libraries and the mobile

- a deposit collection scheme, Books $4 U$ was a major contributor to the increase in the overall issues along with incentive schemes and a change in policies

- encouraging membership on request to use the IT facilities and a change in procedures which allowed members of the public to register to join at community events impacted on increasing the target membership

Qualitative data was collected by conducting face-to-face, semi-structured interviews by purposively sampling a cross section of library staff and community workers. These were audio taped and subsequently transcribed before entering results onto a conceptual matrix for analysing.

The major findings concluded

- An incomplete awareness of the rationale of PSAs and a surprisingly low number of respondents who were able to identify the three targets needed to be met. This could indicate the importance of communication not only in the initial stage but continually throughout the project.

- The need to have strategies, structures and cultures that not only recognise but address barriers to access for users and non-users alike. It appeared that consideration should be given for training staff in an awareness of issues connected with those who are socially excluded.
- Support for the importance of outreach work which, it was felt, should be the responsibility of a number of staff although under the wide co-ordination of the SDO. It was also felt that the work that had been taking place in the deprived wards should extend to the whole service.

- Community workers' responses mirrored those made by library respondents advocating the need to be proactive as opposed to reactive, in order to challenge the way libraries are perceived.

With a $100 \%$ response rate and by sampling varied stakeholders, it would be fair to judge the reliability of results for this study as being unbiased and representative of the wider study population.

The collection of data by using triangulation supports the overall validity of the methods used.

Consequently, it is felt, this study was a useful piece of research resulting in sufficient 'generalisabilty' to enable a generic model to be developed which can be used to provide the framework for future successful outreach work. 


\section{Model to ensure successful project achivement}

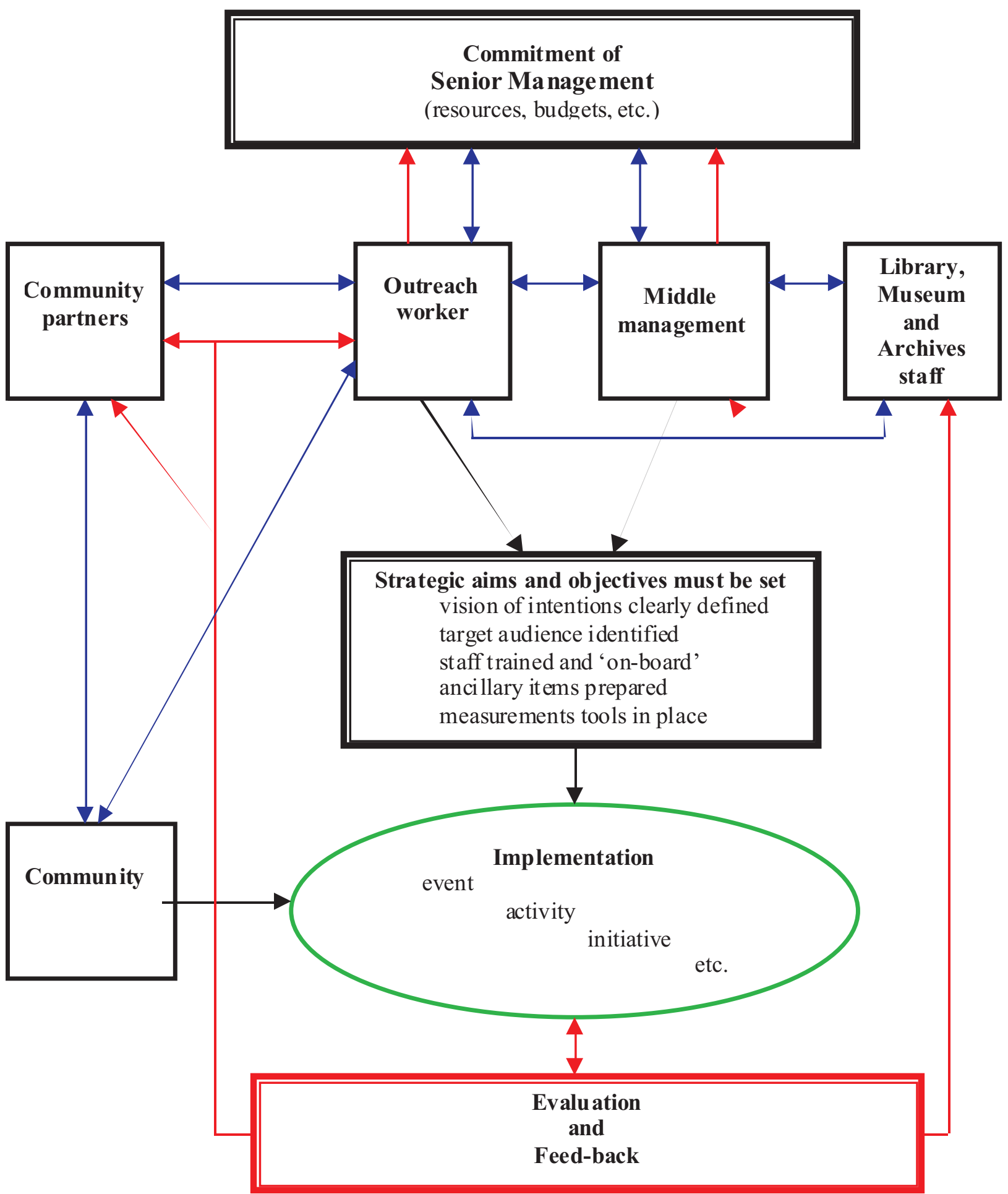

Figure 3 


\section{References}

Black, A. (2000) The public library in Britian 19/4-2000, London: British Library, ISBN pI 45.

Gillham, B. (2000) The research interview, London: Continuum, ISBN

LeCompte, M.D. and Goetz, J.P. (1982) Problems of reliability and validity in ethnographic research. Review of education research, 52 pp.3I-60. Cited by ROBSON, C. (2002) Real world research, $2^{\text {nd }}$ ed. Oxford: Blackwell, p. I07, ISBN 063 I 2 I 3058.

Moore, N. (2000) How to do research: the complete guide to designing and managing research projects, $3^{\text {rd }}$ ed. London: LA, p. I23, ISBN

Patton, M.Q. (1982) Creative evaluation, Newbury Park: Sage, ISBN cited by Robson, C. (2002) Real world research, $2^{\text {nd }}$ ed. Oxford: Blackwell, ISBN 063।2I 3058

Robson, C. (2002) Real world research, $2^{\text {nd }}$ ed. Oxford: Blackwell, ISBN 063/2I3058

Warrington Borough Council. (2002) Draft local public service agreement supporting information., n.p. 